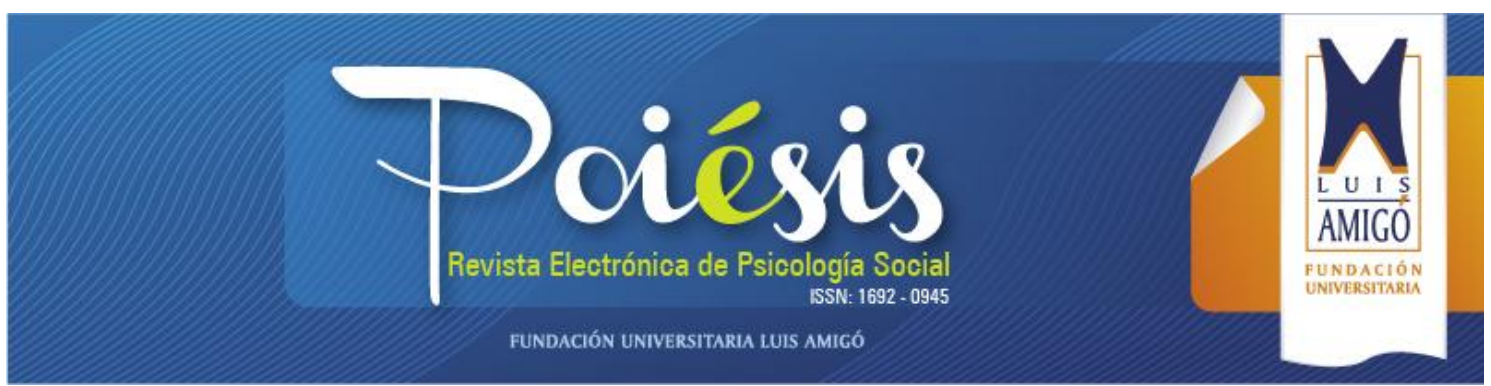

\title{
LA SUBJETIVIDAD MONÁSTICA Y LA CONTEMPORANEIDAD
}

\section{Rogéria Guimarães Alves Bernardes ${ }^{1}$ Leonardo Pinto de Almeida ${ }^{2}$}

\begin{abstract}
RESUMEN
Este artículo pretende analizar la relación entre la experiencia monástica y el capitalismo. Partimos de una comprensión histórica del movimiento monástico cristiano con el objetivo de comprender la peculiaridad de la subjetividad monástica y sus efectos en la actualidad.

Palabras claves: Monacato; Capitalismo; Subjetividad.
\end{abstract}

\begin{abstract}
This article aims to analyse the relationship between the monastic experience and capitalism. We started from a historical understanding of the Christian monastic movement to understand the peculiarity of subjectivity and its effects on monastic nowadays.

Keywords: Monasticism; Capitalism; Subjectivity.
\end{abstract}

\section{Introducción}

Este artículo pretende analizar la subjetividad monástica cristiana, a partir de reflexiones histórico-filosóficas sobre sus peculiaridades y su relación con la época contemporánea. En este sentido, buscamos localizar el movimiento monástico cristiano en relación a la evolución histórica y social de Occidente, destacando sus correlaciones, en particular, con las transformaciones sociales y económicas generadas por el capitalismo, desde sus orígenes hasta la actualidad.

\footnotetext{
${ }^{1}$ Psicóloga e odontóloga. Mestranda do Programa de Pós-Graduação em Psicologia da Universidade Federal Fluminense. E-mail: rogeriabernardes@uol.com.br

2 Doutor em Psicologia pela Pontifícia Universidade Católica do Rio de Janeiro. Professor do curso de Psicologia do PUCG/ UFF e Professor do quadro permanente do Programa de Pós-Graduação em Psicologia da Universidade Federal Fluminense. E-mail: leonardo_almeida@id.uff.br
} 


\section{Capitalismo en sus desdoblamientos}

El momento de transición histórico de la edad media a la edad moderna ocasiona en el mundo occidental una transformación de valores, costumbres y creencias sin precedentes en la historia de la humanidad. El renacimiento urbano y comercial de los siglos XIII y XIV y el crecimiento de la burguesía propician la aparición de otras formas de relación del hombre consigo mismo y con el mundo, favoreciendo a los grandes cambios que están en marcha para los próximos siglos. Los grandes descubrimientos, característicos de los siglos XV y XVI, las nuevas rutas de navegación y el crecimiento de los mercados amplían las fronteras del Occidente, abriendo nuevas oportunidades de mercado y de intercambios, promoviendo una prosperidad hasta ahora desconocida para el comercio, para la industria y para la navegación, temblando, sin duda, la sociedad feudal en desintegración (Marx, 2012).

Todo este movimiento expansionista y mercantil, característico de la transición de la edad media a la edad moderna, prepara el mundo occidental para la gran transformación económica, política y social que iba a suceder, momento en que el vapor y la maquinaria revolucionan la producción industrial, abriendo las puertas al mercado mundial y promoviendo un desarrollo inmensurable del comercio, de la navegación y de las comunicaciones. Encuentran allí, en Inglaterra y en la Revolución Industrial del siglo XVIII, la cuna histórica de esta gran transformación de los procesos de producción de bienes y de acumulación de capital. Esto es un cambio conceptual y estructural definitivo en las relaciones de producción y, en consecuencia, de las relaciones sociales.

Weber (2007) en su obra La génesis del capitalismo moderno nos introduce la atmósfera de este movimiento económico y político, que se diseminó por el Occidente, especialmente en la segunda mitad del siglo XIX, promoviendo cambios definitivos en la relación del hombre con su mano de obra, con la especulación y el lucro, con la acumulación de la riqueza y con los modos de producción. Por lo tanto, es exactamente en el âmbito social que ese movimiento promoverá una transformación sin precedentes, con la disolución de las "relaciones rígidas y oxidadas, con sus representaciones y conceptos 
tradicionales" (Marx, 2012, p. 29). Todos estos cambios estructurales y conceptuales en las relaciones económicas y sociales, que irán caracterizar, en definitivo, este momento histórico, arrastran los otros segmentos de la existencia humana, cuya evolución dará el tono de las sociedades contemporáneas.

Podemos decir que el capitalismo en sus orígenes promueve una gran transformación en las relaciones sociales y productivas. Sin embargo, es posible indicar que, en tiempos contemporáneos, él llega a su mayoridad. En su plenitud actual, él se manifiesta a través de la producción de subjetividad contemporánea, que se revela como algo fabricada, modelada y consumida a escala internacional. Por lo tanto, si estamos inmersos en una sociedad cuya lógica de producción es capitalista - no solo en la producción económica y material, pero fundamentalmente en sus aspectos subjetivos y culturales - nos volveremos en reproductores pasivos de la modelización hegemónica de la subjetividad que proviene de determinaciones colectivas, no sólo sociales, sino también económicas, políticas, tecnológicas, entre otras (Guattari, 2011).

En este sentido, el hombre de hoy, en su actitud libertaria y racional en relación a las creencias sagradas y religiosas establece en la sociedad contemporánea un nuevo tipo de relación de sumisión: se volveré un rehén de una máquina de producción de subjetividad, ligado al modo de ser dominante e hegemónico. La subjetividad capitalista se proyecta, no sólo en la realidad del mundo, sino también en realidades psicológicas, produciendo e influyendo las relaciones humanas, incluso en sus representaciones inconscientes y subjetivas, centrándose en los esquemas de conducta, valores, sentimientos, automatismos, acciones, emociones, deseos, percepciones y pensamientos (Guattari, 2011).

\section{Las singularidades de la vida monástica cristiana}

En esta perspectiva, nuestro desafío es situar y comprender, en el contexto actual, modos de vida que pueden establecer un contrapunto a todo ese movimiento de homogeneización y serialización subjetiva, permaneciendo como posibilidades singulares de afirmación de la existencia. Pensamos que esto se puede vislumbrar con el monacato cristiano, movimiento surgido en el 
siglo IV de la Era Cristiana, con la figura de los "padres del desierto". Estos cristianos, originalmente, anacoretas o ermitaños abandonaban las ciudades para una experiencia más íntima con Dios a través de la soledad, del silencio y de las prácticas ascéticas (Merton, 2011).

Situase allí, en este contexto histórico, especialmente en los desiertos egipcios, pero también en Palestina, Siria y Mesopotamia, el florecimiento de este modo de vida filosófico-religioso que busca rescatar los ideales del cristianismo primitivo. Por abandonar las ciudades para vivir en desiertos deshabitados, estos cristianos (padres del monacato) se dedican a la contemplación, a la oración y al encuentro con Dios, como son experimentados en el inicio del cristianismo. Inaugurase así, el modo monástico de expresión de la fe cristiana, en que el hombre que la practica - el monje - se desvía del mundo (fuga mundi), para en el aislamiento, en el silencio y en la soledad, revivir el modelo de la perfección de los primeros cristianos (Araújo, 2008, p. 43).

Es un hecho que el movimiento monástico cristiano atraviesa la historia de Occidente convirtiéndose en un protagonista silencioso. Bajo el formato de benedictino, él alcanza, en la época medieval, su apogeo influyendo y siendo influenciado por los hechos y los acontecimientos que allí se manifiestan. En la secuencia histórica, él sobrevive al escepticismo religioso y los ideales humanistas revolucionarios, característicos de la edad moderna, llegando a lo contemporáneo, donde sobrevive en discreta pero constante permanencia.

¿Cómo entender, entonces, que un modo de subjetivación como éste, que se afirma en la soledad, en el silencio y en la oración, nacido en el inicio de la Era Cristiana, puede tener sobrevivido tantas revoluciones y transformaciones sociales e históricas y continúe existiendo y resistiendo a los procesos de producción y apropiación del capitalismo contemporáneo?

\section{¿Posibles entrecruzamientos?}

Guattari (2011) llama la atención sobre las posibilidades de resistencia a los modos hegemónicos impuestos por la dinámica capitalista. Según él, los 
procesos de singularización, en que se identifican las relaciones de expresión y creación, se oponen a la subjetivación fabricada y modelada del capitalismo.

En este sentido, aunque podemos reconocer en el en modus vivendi monástico esa singularización subjetiva, que se afirma con sus costumbres, preceptos, prácticas ascéticas y, principalmente, en la expresión de la fe cristiana, pensamos que la mayor especificidad de este grupo social es, de hecho, su capacidad para resistir los procesos históricos, de los cuales el capitalismo sería sólo uno más. En el caso de un movimiento de más de quince siglos y, por tanto, mucho antes de que la subjetividad capitalista consolidarse como hegemónica, la singularidad de esta forma de vida existe menos en su oposición a las formas predominantes de subjetivación en las sociedades de consumo, que en su capacidad para resistir y convivir con esos modos.

Para alejarse del mundo y hacer la elección de un estilo de vida que renuncia al ejercicio de la voluntad, a los deseos personales, al derecho a la propiedad, a la comodidad y bienestar, al orgullo, al derecho a fundar una familia, a la opción de tener su tiempo y vivir de su manera, el monje se vuelve, de hecho, en un peregrino en la existencia, despojado de todo como los eremitas del desierto $y$, en este sentido, invulnerable a cambios, transformaciones e influencias, sea de las prácticas capitalistas o de cualesquier otra que pueda surgir.

\section{Referencias Bibliográficas}

Araújo, A.(2008). Dos livros e da leitura no Claustro: elementos de história monástica, de história cultural e de bibliografia histórica para estudo da Biblioteca-Livraria do Mosteiro de São Bento de São Paulo (Sécs. XVI-XVIII). Dissertação (Mestrado em História), Faculdade de Filosofia, Letras e Ciências Humanas, Universidade de São Paulo São Paulo: USP/SP.

Guattari, F. \& Rolnik, S. (2011). Micropolítica: Cartografias do desejo. Petrópolis, RJ: Vozes.

Marx, K. (2012). Manifesto do partido comunista. Porto Alegre: L\&PM.

Merton, T. (2011). A vida silenciosa. Petrópolis, RJ: Vozes, 2011.

Weber, M. (2007). A gênese do capitalismo moderno. RJ: Ática. 